\title{
The Epidemiology of Students Injuries in a Private Primary School in Turkey from 2012 to 2018
}

\author{
Ayşe Şengel ${ }^{1}(\mathbb{D})$, Kamer Gür ${ }^{2}$ (D) Eda Kılınç ${ }^{3}$ (D) \\ ${ }^{1}$ Açı Schools, Istanbul, Turkey. \\ ${ }^{2}$ Marmara University, Faculty of Health Sciences, Department of Public Health Nursing, Istanbul, Turkey. \\ ${ }^{3}$ Pamukkale University, Faculty of Health Sciences, Department of Public Health Nursing, Denizli, Turkey. \\ Correspondence Author: Eda Kılınç \\ E-mail: ekilinc@pau.edu.tr
}

Received: $22.11 .2019 \quad$ Accepted: 14.08 .2020

\begin{abstract}
Objective: The aim of this study is to identify the occurrence frequency of school injuries, and to report where, when, and why they occur most.

Methods: This retrospective descriptive study includes students aged between 6 and 11 years and is composed of 7042 school injury records. The school was chosen by the purposive sampling method since there was a school nurse working at school. The school injury records were formed by all injury records kept by the school nurse. The data were evaluated using descriptive statistics.

Results: The study results showed that most of the school injuries occurred during the fall period $(60.1 \%)$ and at break times (38.6\%). As for the causes of the injuries, $13.3 \%$ of them were environmental, while $86.7 \%$ were behavioral. The floor on where most of the injuries occurred was rubber floor (53.6\%) and the area where most of the injuries occurred was playground-garden (64\%). The factor most frequently causing the injuries was hit collision, and the activity causing most of the injuries was running. The most frequently affected part of the body was headneck-forehead-chin. The most common type of injury was tenderness and redness.

Conclusion: With this study, it is seen that the rate of injury among students is high. Most of the school injuries occurred during the break times and mealtimes. Most of the causes of injuries were behavioral. These epidemiological data would be a guide for studies on prevention of injuries.
\end{abstract}

Keywords: Wounds and injuries, epidemiology, schools, nursing.

\section{INTRODUCTION}

Injury is defined as intentional or unintentional damage to the body. These injuries generally include drowning, poisoning, falling, burning, violence, assault, self-harm and war $(1,2)$. School injuries are unintentional injuries. As environments preparing children for life, schools also present some environmental risks. Risk factors for childhood injuries are related to factors such as locomotor skills, individual attention and control, emotional stress, psychological problems, physical activity, susceptibility to accident, problematic risk-taking behaviors, socio-economic and family factors, communication with schoolmates (3). Other than the risk factors related to child and family, the most common causes of injury among school-age children are male gender, physical condition of the school, school administration and wrong policies (1,3).

A study from Turkey investigating the risk factors that caused the injury showed that $53.6 \%$ of the risks stem from the child himself/herself, 37.5\% from another child, 5.4\% from school uncertainty and lack of control, and 3.6\% from the school's environmental factors (4). In another study, most of the risk factors have arisen from the child himself/herself, the irregularity and lack of control at school and the insufficient environmental factors at school (5).

School injuries are considered a major cause of death and disability among children in Europe and are an important public health problem around the world (2). The rate of school injuries varies by countries and regions. The rate of school injuries in global studies ranges from $5 \%$ to $54 \%(6-8)$. In the studies conducted in Turkey, this ratio is between $9 \%$ and $55.4 \%(4,9,10)$.

Injuries experienced by children can lead to permanent disability, physical problems and psychological problems both for them and their families. In addition, family and country economy are adversely affected by the medical costs resulting from these problems and the cessation of productivity $(11,12)$.

It is essential for health professionals to identify the causes of school injuries to take measures against these negative consequences. Causes of school injuries can be attributed to students' individual characteristics (aggressive 
behavior, loco-motor skills, physical activity, student profiles, susceptibility to injury, socio-economic and familial factors, interaction with school friends) and environmental characteristics of schools (ecological characteristics, dangerous activities, sports activities, playground) (3). Kılınç reported that $18.9 \%$ of the school children had at least one injury at school (13).

Areas where school injuries most commonly occur are the road to and from school, the classroom environment, gym, garden, corridor, cafeteria and canteen $(1,8,13)$. The most dangerous areas where students experience injuries are gyms and school gardens (3). About four million children and adolescents aged 10 to 17 around the world are injured at school, and more than 1 million of them are injured while doing sports every year (14). The activities that most commonly lead to sports injuries are football, basketball, and volleyball, respectively (13).

In general, risks should be recognized to take adequate measures for injuries. Preventing school injuries is a key role for school nurses. It is school nurse's responsibility to identify risk factors by assessing the characteristics of the child, family and school environment. School nurses, who are responsible for the health of children, can test the benefits of safety measures in their research, and instill the awareness of preventing accidents to those who regulate the laws. They can take the advocacy role in the formation of legal regulations on accident prevention and attract the public's attention with their research. In addition, they can promote prevention and control of injuries by providing training and improving environmental protection strategies $(3,15)$.

Another important group that should be sensitive in taking necessary precautions against the risks of injuries is the school administration $(1,15,16)$. In addition to a school administration taking all necessary measures with the required planning and arrangement, it is very important that children have the necessary knowledge and health belief to protect themselves from injuries $(15,17,18)$. Parents also play a critical role in this regard because behaviors of parents before or after injuries are of importance in reducing the risk of injuries caused by the school environment and protecting children from injuries $(1,16)$.

We believe that the findings of this study will guide school administrations, school nurses, teachers, students and parents by identifying the risk factors that lead to school injuries and answering questions 'when, where and during which activity the injuries occur' and 'what efforts are made after the injury'. The aim of this study is to identify the frequency of occurrence of school injuries, and to report where, when and why they occur most.

\section{METHODS}

\subsection{Study Design and Participants}

This retrospective descriptive study examined the epidemiology of school injuries occurred between September
2012 and June 2018. The study consisted of all the injury records of first, second, third and fourth grade students who were injured at a private school in Istanbul during this period. The school was chosen by the purposive sampling method since there was a school nurse working at school. The school injury records were formed by 7042 injury records kept by the school nurse.

There was a school nurse in the campus where the research was conducted and the nurse was working at the infirmary serving 350 students and 120 employees. In the school where the research was carried out, students were organized to use playgrounds so that each level could take a break at different hours. The school had two playgrounds $\left(500 \mathrm{~m}^{2}\right)$ in common areas, one large garden $\left(500 \mathrm{~m}^{2}\right)$ and two gyms (one indoor-one open).

The socio-economic conditions of the students enrolled in the school were quite good and their parents' education level was high. The institution and accessibility of the researcher were taken into consideration in the selection of the school where the research was conducted.

\subsection{Data Collection Tools and Procedures}

Data was obtained from the forms filed by the school nurse. The 'School Injury Form' was created by Gür and tested at a two-week preliminary study and finalized with the necessary arrangements; the preliminary study was conducted on 50 primary school students in 2004 (19). This form can easily be filled in for any student injured by the school nurse. The form filled in for each injured student was stored by the school nurse in the school injury file.

Since the data was entered by the nurse and regularly checked, no missing data was detected. Data was entered into the data set by the researchers within a period of 2 weeks. The number of responses of each item might vary. The questions included 'when and where the student had the injury at school, the type of injury, the injured body area, and the activities that caused the injury'. The students were categorized by characteristics such as gender, injury time at school, and injury type. Information about the injury-causing activity, area of the injury, time of occurrence, type of injury, and the post-injury intervention was obtained for each student.

\subsection{Data Analysis}

Data was evaluated by IBM Predictive Analytics Software (PASW) Statistical Product and Service Solutions (SPSS, Chicago, IL, USA) version 22. The data analysis utilized frequency, percentage, mean \pm standard deviation for the epidemiology of school injuries.

\subsection{Ethical Consideration}

This study was ethically approved by TR Pamukkale University Non-Invasive Clinical Research Ethics Committee (10.07.2018-14). The records of the study were used with 
the written permission of the school administration and the school nurse.

\section{RESULTS}

A total of 7042 school injury records were examined. The mean age of 7042 students who had an injury at school was $8.36 \pm 1.26(\min =6 ; \max =11) .60 .4 \%$ of the students were boys and $39.6 \%$ were girls (Table 1 ). There were also recurrent records of students among these injury records.

Table 1. Sociodemographic Characteristics and Injury Records $(n=7042)$

\begin{tabular}{|l|c|c|c|}
\hline \multicolumn{2}{|c}{ Characteristics } & \multicolumn{2}{c|}{$\mathbf{n}$} \\
\hline \multirow{3}{*}{ Gender } & Boy & 4253 & 60.4 \\
\cline { 2 - 4 } & Girl & 2789 & 39.6 \\
\hline \multirow{4}{*}{ Age } & $\mathbf{6}$ & 326 & 4.6 \\
\cline { 2 - 4 } & $\mathbf{7}$ & 1737 & 24.7 \\
\cline { 2 - 4 } & $\mathbf{8}$ & 1895 & 26.9 \\
\cline { 2 - 4 } & $\mathbf{9}$ & 1483 & 21.1 \\
\cline { 2 - 4 } & $\mathbf{1 0}$ & 1352 & 19.2 \\
\cline { 2 - 4 } & $\mathbf{1 1}$ & 249 & 3.5 \\
\hline
\end{tabular}

By years, school injuries were most frequently seen between 2012 and 2013 (Figure 1). School injuries most frequently occurred during break times, meal time, lunch break and leisure time (77.1\%). It was found that most of the injuries occurred in the fall term, in December and between the hours 12:01 and 14:00 (Table 2).

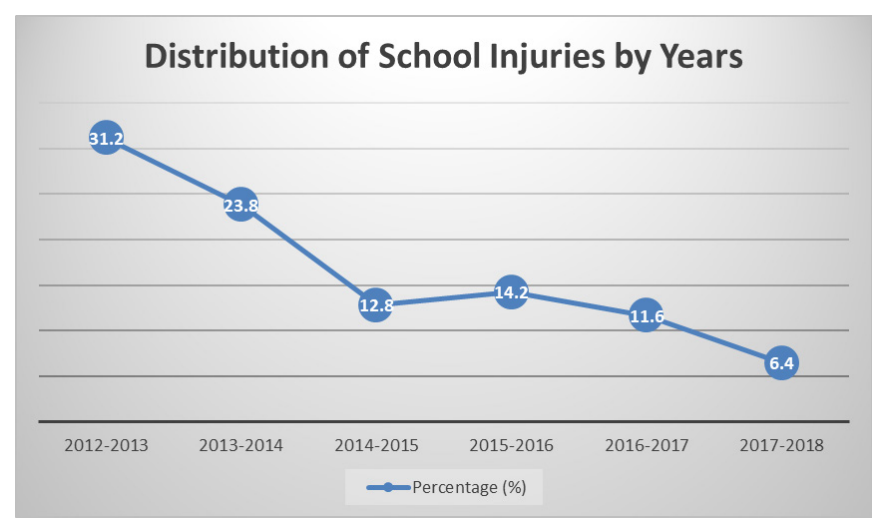

Figure 1. Distribution of School Injuries by Years $(n=7042)$

As for the causes of the injuries, $13.3 \%$ of then were environmental while $86.7 \%$ were behavioral. The factor causing most of the injuries was hit-collision (46.8\%), and the activity causing most of the injuries was running (40.5\%). The floor on where most of the injuries occurred was rubber floor and the area where most of the injuries occurred was playground-garden (Table 3).

The most frequently affected part of the body was head-neckforehead-chin (31.4\%) (Figure 2). The most common type of injury was tenderness (99.7\%) and redness (19.0\%) (Figure 3).
$19.3 \%$ of the students were subjected to activity restriction after the injuries, and only $0.7 \%$ of them were absent from the school. All the students at the school were given first aid by the school nurse, families of $53.6 \%$ were informed, and $0.3 \%$ of them were referred to a healthcare clinics/hospital after the injuries.

Table 2. School Injuries by Periods, Times and Hour Intervals $(n=7042)$

\begin{tabular}{|l|l|c|c|}
\hline \multirow{4}{*}{ Term } & Fall & n & \% \\
\hline \multirow{5}{*}{ Month } & & 4230 & 60.1 \\
\cline { 2 - 4 } & Spring & 2812 & 39.9 \\
\hline \multirow{5}{*}{} & September & 686 & 9.7 \\
\cline { 2 - 4 } & October & 827 & 11.7 \\
\cline { 2 - 4 } & November & 908 & 12.9 \\
\cline { 2 - 4 } & December & 943 & 13.4 \\
\cline { 2 - 4 } & January & 608 & 8.6 \\
\cline { 2 - 4 } & February & 521 & 7.4 \\
\cline { 2 - 4 } & March & 898 & 12.8 \\
\cline { 2 - 4 } & April & 794 & 11.3 \\
\cline { 2 - 4 } & May & 472 & 6.7 \\
\cline { 2 - 4 } & July & 385 & 5.5 \\
\hline \multirow{5}{*}{ Hours } & Between 08.00-10.00 & 692 & 9.8 \\
\cline { 2 - 4 } & Between 10.01-12.00 & 1981 & 28.1 \\
\cline { 2 - 4 } & Between 12.01-14.00 & 2721 & 38.6 \\
\cline { 2 - 4 } & Between 14.01-16.00 & 1648 & 23.4 \\
\hline
\end{tabular}

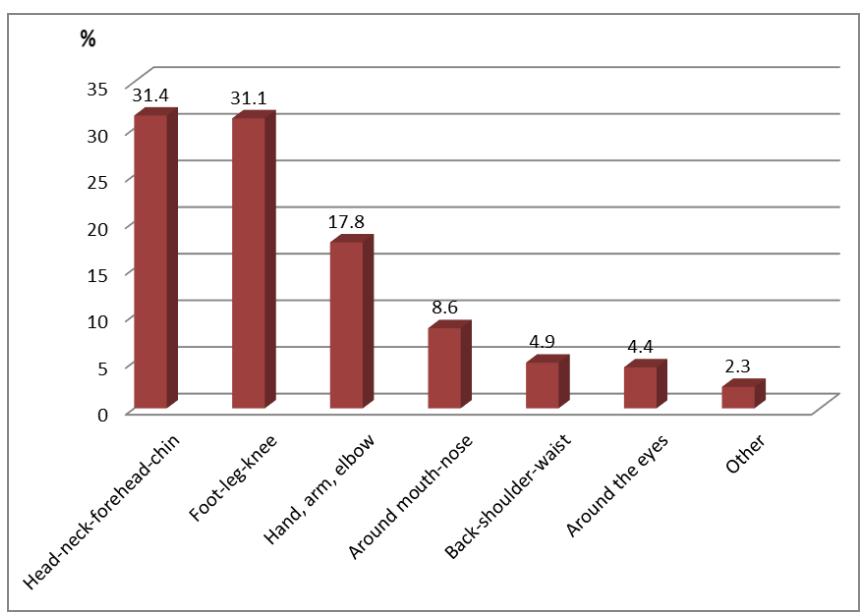

Figure 2. Body areas affected with school injury ( $n=7042)$

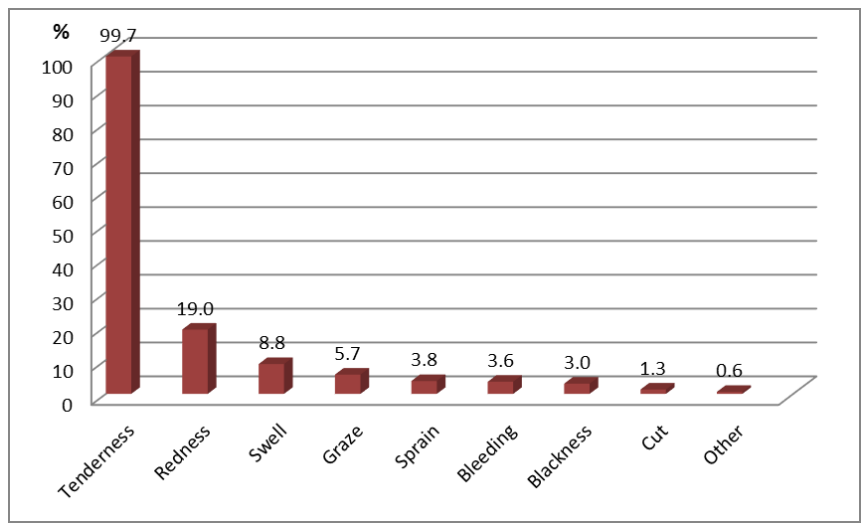

Figure 3. Types of injuries and symptoms caused by school injury $(n=7042)$ 


\begin{tabular}{|c|c|c|c|}
\hline & & $\mathbf{n}$ & $\%$ \\
\hline \multirow{2}{*}{ Cause of injury } & Environmental & 937 & 13.3 \\
\hline & Behavioral & 6105 & 86.7 \\
\hline \multirow{7}{*}{$\begin{array}{l}\text { Factor causing the } \\
\text { injury }\end{array}$} & Collision-hit-strike & 3294 & 46.8 \\
\hline & Falling & 2316 & 32.9 \\
\hline & $\begin{array}{l}\text { Injury with a tool/ } \\
\text { object }\end{array}$ & 962 & 13.7 \\
\hline & Sprain & 246 & 3.5 \\
\hline & $\begin{array}{l}\text { Getting stuck - } \\
\text { jamming }\end{array}$ & 183 & 2.6 \\
\hline & Animal bite - scratching & 24 & 0.3 \\
\hline & Heat - electricity & 17 & 0.2 \\
\hline \multirow{10}{*}{ Sports injuries } & Running & 2850 & 40.5 \\
\hline & Pushing around & 2214 & 31.4 \\
\hline & Walking & 578 & 8.2 \\
\hline & Football & 465 & 6.6 \\
\hline & Volleyball & 359 & 5.1 \\
\hline & Sitting & 246 & 3.5 \\
\hline & Basketball & 171 & 2.4 \\
\hline & Slipping & 72 & 1.0 \\
\hline & Jumping & 50 & 0.7 \\
\hline & Riding on a swing & 37 & 0.5 \\
\hline \multirow{5}{*}{ Floor of injury } & Tartan (rubber) floor & 3777 & 53.6 \\
\hline & $\begin{array}{c}\text { Asphalt-concrete-tile- } \\
\text { ceramic }\end{array}$ & 2409 & 34.2 \\
\hline & Carpet-rug-mat & 660 & 9.4 \\
\hline & Gravel-sand-grass-soil & 187 & 2.7 \\
\hline & $\begin{array}{l}\text { Slippery floor-frosted- } \\
\text { wet }\end{array}$ & 9 & 0.1 \\
\hline \multirow{8}{*}{ Area of injury } & $\begin{array}{l}\text { Garden-playground- } \\
\text { park }\end{array}$ & 4505 & 64.0 \\
\hline & $\begin{array}{c}\text { Classroom-library- } \\
\text { events }\end{array}$ & 1490 & 21.2 \\
\hline & Gym & 447 & 6.3 \\
\hline & Corridor-stairs & 440 & 6.2 \\
\hline & Cafeteria-canteen & 70 & 1.0 \\
\hline & Toilet & 41 & .6 \\
\hline & $\begin{array}{c}\text { School service-school } \\
\text { premises }\end{array}$ & 37 & .5 \\
\hline & Lab & 12 & .2 \\
\hline
\end{tabular}

\section{DISCUSSION}

Our study showed that boys had more injuries than the girls. In the literature, it was also observed that boys more frequently had injuries than girls $(6,9,10,13)$. The fact that boys had injuries more frequently than girls might be due to riskier behaviors of boys, their stronger physical activity levels and aggressive structures, and harsher behaviors and understanding of game between boys as well as the cultural structures in which parents and society have different expectations from the male character. Therefore, it is thought that the rate of injuries experienced by boys is higher as they are more prone to risky behaviors $(10,20)$. 
When individual factors affecting school, injuries were examined; the age factor was found to be important $(3,10,21)$. In our study, the age range that students experienced injury most frequently was between the ages of seven and nine. Cognitive and behavioral skills of school children are immature (their physical condition is weak and prone to clumsiness). Elementary school children are curious, investigative and unaware of the dangers, creating a high risk of injuries $(8,3,19)$.

In our study, school injuries decreased compared to years. Information was obtained from the school nurse about the reason for this situation. Accordingly, the reason for this situation was the training provided by the school nurse to prevent injuries. In addition, it is thought that this might have been affected by the improvement of the school's physical security structure. Researches in the literature also indicate that providing education and increasing school security reduces injuries $(3,15,18)$.

It was observed that most of the school injuries occurred during break times, lunch break-meal time or leisure time. Other studies in the literature determined that most of the injuries occur during the break times $(8,10,13,21)$. Break times are among the periods in which children rush up and down the stairs when going to the canteen and push each other around in and outside school, that is, they are at their most active time. It is thought that the increase in injuries is caused by their desire to get out of classrooms where they are kept under control and most of their behaviors are restricted and to act more uncontrollably when the bell for the break time rings. As in other studies $(10,21)$, it is thought in this study that the reason why most of the school injuries were observed in December and at noon might have been the increased incidents of slipping during snow and rainfall in winter and noon being the most energetic time for children.

School injuries can be caused by the students' own behaviors as well as by the unsafe school environment (3). This study found that $13.3 \%$ of the causes of injuries were environmental while $86.7 \%$ were behavioral. Akçay and Yıldırımlar observed that $3.6 \%$ of the injuries were due to environmental factors while Gevrek Akar found a rate of $17.3 \%(4,5)$. Although student behaviors are highly effective in the occurrence of injuries, the risks of school safety need to be minimized.

It was observed in our study that the factors causing most of the school injuries were hit-collision, falling, and injury by a device while the activities causing the most school injuries were running, pushing around, walking, football and volleyball. In other studies, on school injuries $(5,8-10,13)$, falling, collision, running, walking, and playing football, volleyball and basketball were among the factors and activities that cause injuries. The reason for this finding might be the fact that children act carelessly and without protecting themselves during physical education classes, break times and leisure times and do sports without protecting themselves, warming up and wearing protective equipment. To prevent injuries, it is necessary that students are told not to prefer slippery shoes and run on slippery surfaces in the school and school administration put warning signs near slippery floors, and to prevent sports injuries, training and counseling should be provided about warming up and wearing protective equipment (kneepads, elbow pads, etc.) before doing sports.

As for the floor and area of injuries, most of the injuries occurred on tartan (rubber) floor which was followed by asphalt-concrete-tile floor whereas most of the injuries occurred in garden-playground, classroom, gym and corridors-stairs. It is thought that injuries were more frequent in areas such as playgrounds, gardens, corridors and stairs where students are the most active; this finding is in line with those of other studies $(5,8-10,13)$. However, in our study, the reason why the floor where most of the injuries occurred on was tartan (a two-layer, water-permeable, granular, flexible sports floor made of rubber) is that garden and sports areas of the school where the was conducted were tartan-covered. As explored by national and international studies, since the most used building materials in and outside the school are concrete and asphalt, these hard floors cannot absorb the fall-related impact and can lead to severe symptoms as a result of injury (22-24). It should be ensured through the cooperation with school administration to cover school gardens and playgrounds with rubber-content materials to prevent these severe injuries.

In our study, head-neck-forehead-chin body region was affected the most after the students' injury. Then, the extremities (foot-leg-knee, hand, arm, elbow) were affected. In the study of Gür, in primary school students, it was determined that the head and extremities were affected the most (19). In the study of Eraslan and Aycan, research results are in line with our study results (10). Students' being constantly in motion and fall and collision while running, sliding, jumping, doing sports and climbing is the most common cause of head injuries. According to our study, the extremities are the most injured area of the body. This is thought to be due to the individuals protecting their vital organs with the help of extremities during injury $(13,19)$.

In our study, most frequently tenderness, redness, swelling and graze occurred as the types of injuries. In Özkan's work, the most common types of injuries were graze, swelling and bruising (25). In the study of Gür, swelling, tenderness and graze were observed the most (19). In the study of Eraslan and Aycan, hurt, sprain, bruising, swelling and graze occurred the most (10). The leading reason for this is that the causes of injury are mostly falling, crashing, and sports-related (19).

Our study showed that all the students who had a school injury were given first aid by the school nurse, only $0.3 \%$ of them were referred to the health institution, and $0.7 \%$ were absent from the school. In other studies, the rate of referral to health institutions varied between 7.5 and $35.2 \%$ $(5,10,13)$. The reason can be associated with the high rate of referral of students to hospital and the low rate of first aid. Şengel and Gür observed that all of the students were given first aid by the school nurse after the injury, only $1.9 \%$ of the students applied to the infirmary due to injury in the last two years, and only $1.9 \%$ were absent from the school (21). 
Akçay and Yıldırımlar reported that the first intervention was performed to the students by their teachers (64.3\%) and the school health personnel (8.9\%), and $37.5 \%$ of the students went to the hospital/visited a physician after the injury (4). In the study of Ayaz, 92.7\% of the primary school teachers stated that school nurses were required at school (26). These findings indicate that students are mostly referred to health institutions and students' absenteeism is increased in schools that do not employ school nurses. It was also shown in international studies that nurses are effective and needed to prevent school injuries $(27,28)$.

School administration, teachers, parents, and most importantly, school nurses play a key role in this matter. The duties and powers of school health nursing were published in the Official Gazette on 19 April 2011 (29). In this regulation, "School Health Nursing" falls within the scope of Public Health Nursing and have several roles. The article "he/she cooperates with students, families, school administrations and educators in improving the prevention of injuries and safety precautions" sets one of the school nurse's duties, powers and responsibilities. In this context, school nurses should develop intervention programs with existing research evidence and cooperation with school administration to create a safe school environment. Such intervention programs based on models that provide behavioral change such as health belief model can contribute to their effectiveness (18,30-33).

In this context, establishing a safe school environment through employment of school health nurses who are effective in protecting, improving and maintaining students' health, preventing injuries and injuries, giving first aid to students who have had an injury are required for the continuation of a healthy society.

\section{Limitations}

The main limitation of the present study is the limitation of generalizability of the results due to results from only one private school. The institution and accessibility of the researcher were taken into consideration in the selection of the school where the research was conducted. The school was chosen by the purposive sampling method since it is a school nurse at school.

\section{CONCLUSION}

Our study found out that boys had injuries more frequently, most of the injuries occurred during break times and lunch times, were caused by behavioral problems and as a result of hit, and the activity which caused the most of injuries was running. It was determined that the injuries in the school were mostly experienced on rubber ground and that they were mostly in playgrounds and gardens. After the accidents, the head and extremity areas of the students were injured the most. The most common injury after the accident is tenderness, redness, swelling and graze. School nurses made first aid interventions for all injured students.
Thus, unnecessary referrals to healthcare institutions were prevented.

It is accordingly recommended that school nurses who can provide extensive school healthcare service are employed in every school to create safe schools; non-slippery, rubber floors which dampens the fall impact are used to minimize environmental risk factors in all schools. In addition, more extensive epidemiological studies for school injuries are recommended.

\section{Acknowledgment}

All authors contributed to data collection process and writing of the manuscript.

\section{Conflict of Interest}

The author(s) declared no potential conflicts of interest with respect to the research, authorship, and/or publication of this article.

\section{REFERENCES}

[1] Gür K, Yıldız A. Development of scales of pupils' knowledge and attitude towards the security prevention against school accidents. Maltepe University Journal of Nursing Science and Art 2009; 2(1):10-21.

[2] Sethi D, Towner E, Vincenten J, Segui-Gomez M, Racioppi F. Child Injuries in The WHO European Region. European Report on Child Injury Prevention. Int: 2008. Report No: 1.

[3] Gür K. Special problems in school health; school accidents. Gözüm S, editor. Developing the Health of Children in School Period. Istanbul: Vize, Turkey; 2016.p.399-410.

[4] Akçay D, Yıldırımlar A. Investigation of parental behaviors of children in accident and security measures in school environment. DEUHEFED 2018; 11(1):48-55.

[5] Gevrek Akar S. Investigation of The Effects of Security Measures Taken in Primary Education Institutions on School Accidents. Istanbul Medipol University. Health Sciences Institute, Master Thesis. 2017.

[6] Khan UR, Bhatti JA, Zia N, Farooq U. School-based injury outcomes in children from a low-income setting: results from the pilot injury surveillance in Rawalpindi city, Pakistan. BMC Research Notes 2013; 6(86):1-6.

[7] Apostolico AA, Shendell DG. Injury surveillance and associations with socioeconomic status indicators among youth/young workers in New Jersey secondary schools. Environmental Health 2016; 15(22):1-9.

[8] Sun YH, Yu ITS, Wong TW, Zhang Y, Fan YP, Guo SQ. Unintentional injuries at school in China-patterns and risk factors. Accident Analysis Prevention 2006; 38(1):208-214.

[9] Yertutan C, Erkal S. Determine the situation of students' having an accident in the school and the parents' behaviors aimed at preventing them from having an accident in the school. Hacettepe University Sociological Research E-Journal (serial online) 2010 (cited 2019 Nov 1). Available from: http://www. sdergi.hacettepe.edu.tr/makaleler/sibelerkalcananyertutan. pdf. 
[10] Eraslan R, Aycan S. The study of the freqency of the school accidents in the secondary school children. Turkish J Pediatr Dis 2008; 2(1): 8-18.

[11] Forum on Child and Family Statistics. Adolescent injury and mortality, 2017. Retrieved August 10, 2019 available from: https://www.childstats.gov/americaschildren/phys8.asp.

[12] Santoro K, Schoenman J. Preventing adolescent injury: the role of health plans, 2018. Retrieved November 01, 2019 available from: https://www.childrenssafetynetwork.org/resources/ preventing-adolescent-injury-role-health-plans.

[13] Kılınç E, Gür K. Behaviours of adolescents towards safety measures at school and in traffic and their health beliefs for injuries. Int J Nurs Pract 2020; 26(5):e12861.

[14] Centers for Disease Control and Prevention (CDC). Healthy youth! Unintentional injuries, violence and the health of young people 2016. Retrieved November 07, 2018 available from: http://www.cdc.gov/healthyyouth/injury/facts.htm.

[15] Kılınç E, Gür K. The effect of health belief model based initiatives in preventing school injuries. HSP 2018; 5(3):467475.

[16] Philbrook JK, Kiragu A, Geppert J, Graham P, Richardson L, Kriel R. Pediatric injury prevention: methods of booster seat education. Pediatric Nursing 2009; 35(4):215-220.

[17] Kılınç E, Gür K. Turkish validity and reliability of health belief model based injury scale. Turkiye Klinikleri J Nurs Sci 2019; 11(1):25-34.

[18] Cao ZJ, Chen Y, Wang SM. Health belief model based evaluation of school health education programme for injury prevention among high school students in the community context. BMC Public Health 2014; 14(26):1-8.

[19] Gür K. Epidemiology of Accident in the Elementary Schools of Istanbul and Development of Scales of Children's Knowledge and Attitude Towards the Security Prevention Against School Accidents. Marmara University. Health Sciences Institute, PhD Thesis. 2005.

[20] Özakar Akça S, Yıldız S. Risk-taking behaviors in adolescents and approach to adolescent. Literature Symposium 2015; 2(6):14-22.

[21] Şengel A, Gür K. Unintentional injuries and school absenteeism in a private primary school: a 2-year retrospective study. 1th Public Health Nursing Congress; 2015 July 17-20; Izmir: Turkey; 2015. pp: 183.
[22] Geller RJ, Rubin IL, Nodvin JT, Teague WG, Frumkin H. Safe and healthy school environments. Pediatr Clin N Am 2007; 54(2):351-373.

[23] Arslan Muhacir ES, Yavuz Özalp A. Determination of quality and quantity for primary schoolyards in Artvin city center by using geographical information system. ACU J For Fac 2011; 12(2):172-184.

[24] Samur AÖ, Kızıltepe Gi. Investigation of children's playgrounds in Aydın province. DDRJ 2018; 7(1):31-46.

[25] Özkan, O. Incidence and outcomes of school-based injuries during four academic years in Kocaeli, Turkey. Pediatrics International 2016; 58(8):732-739.

[26] Ayaz S. Opinions of elementary school teachers regarding school health nursing. JOHUFON 2014; 1(2): 42-52.

[27] Li L, Scherpbier R, Wu J, Zhu X, Zhang W, Zhang L. et al. Legislation coverage for child injury prevention in China. Bull World Health Organ 2015; 93(3):169-175.

[28] Wyman L. Comparing the number of ill or injured students who are released early from school by school nursing and nonnursing personnel. JOSN 2005; 21(6):350-355.

[29] Official Gazette, Ministry of Health: Regulation on Amendment to the Nursing Regulation. Number: 27910. Retrieved January 13, 2019 available from: Retrieved from: http://www. resmigazete.gov.tr/eskiler/2011/04/20110419-5.htm.

[30] Zhang LL, Dalal K, Wang SM. Injury related risk behavior: a health belief model-based study of primary school students in a safe community in Shanghai. PLoS One 2013; 8(8):e70563.

[31] Rezapur-Shahkolai F, Ebrahimikhah M, Hazavehei SMM, Moghimbeigi A. Using health belief model on preventive behaviors related to road traffic injuries among primary school students. JRH 2016; 7(4):908-914.

[32] Farhadi Z, Roshanaei G, Bashirian S, Rezapur-Shahkolai F. The effect of an educational program on school injury prevention in junior high school students of Famenin based on the health belief model. J Educ Community Health 2014; 1(3):1-11.

[33] Kartal A, Kılınç E. School based training programs for preventing injuries: systematic review. ESTÜDAM Public Health Journal 2020; 5(1):131-141. 